Louisiana State University

LSU Digital Commons

Faculty Publications

Department of Biological Sciences

$4-1-2007$

\title{
Introduction for the Gene special issue dedicated to the meeting "Genomic impact of eukaryotic transposable elements" at
}

\section{Asilomar}

\author{
Mark A. Batzer \\ Center for BioModular Multi-Scale Systems \\ Prescott L. Deininger \\ Tulane University School of Public Health and Tropical Medicine \\ Jerzy Jurka \\ Genetic Information Research Institute \\ John V. Moran \\ University of Michigan Medical School
}

Follow this and additional works at: https://digitalcommons.Isu.edu/biosci_pubs

\section{Recommended Citation}

Batzer, M., Deininger, P., Jurka, J., \& Moran, J. (2007). Introduction for the Gene special issue dedicated to the meeting "Genomic impact of eukaryotic transposable elements" at Asilomar. Gene, 390 (1-2), 1-2. https://doi.org/10.1016/j.gene.2006.07.036

This Editorial is brought to you for free and open access by the Department of Biological Sciences at LSU Digital Commons. It has been accepted for inclusion in Faculty Publications by an authorized administrator of LSU Digital Commons. For more information, please contact ir@lsu.edu. 


\section{Introduction for the Gene special issue dedicated to the meeting "Genomic impact of eukaryotic transposable elements" at Asilomar}

This Special Issue of Gene - Evolutionary Genomics - is dedicated to the Symposium "Genomic Impact of Eukaryotic Transposable Elements", which took place in Pacific Grove, California between March 31st and April 4th 2006 and was organized by the four Editors of this issue.

This was the first meeting organized by the Genetic Information Research Institute associated with a workshop centered on a database of repetitive DNA known as "Repbase". We are grateful to the National Institutes of Health, Tulane University Health Sciences Center and Louisiana State University for providing support for the meeting.

Beginning with Barbara McClintock, studies of transposable elements (TEs) were braved by individuals or small research groups, and considered by some as "obscure" or "out of the mainstream". Retrospectively, this invaluable effort prepared the foundation for the genome sequencing era that rapidly placed transposable elements at the front and center of exciting new interdisciplinary research efforts. Therefore, the meeting was a fitting occasion to celebrate and honor the extraordinary contributions of Dr. Carl W. Schmid to the study of repeated DNA sequences and mobile elements. We used the occasion of his birthday to have a series of talks focused on the field of mammalian retroelements. Carl began contributing to this field before we knew about retroelements, with early studies on Drosophila and human repetitive DNA using the relatively blunt tools of reassociation kinetics. With the advent of recombinant DNA technology he led the discovery of human Alu elements, and the discovery of the characteristics that we now know drive their amplification. He has actively contributed to this field for over three decades, discovering important aspects of Alu expression, modification, evolution and activity. In addition, he has been an outstanding mentor to many others who have also contributed to the field of mobile elements, and selflessly played critical leadership roles at UC Davis. Many of us believe that without his efforts the field would have floundered.

The only identifiable, universal 'function' of transposable elements appears to be their own survival, which makes them subject to Darwinian selection and evolution in the context of their 'genomic ecosystems'. As they reproduce, evolve and survive in a tightly regulated host environment, TEs drive diverse evolutionary changes in the genome and may contribute to organismal diversity. Many of these changes have been recorded in TE-derived genes and in multiple layers of interspersed repetitive DNA. This treasure trove of information becomes increasingly available through public databanks and urgently needs to be excavated, processed, catalogued and studied in both wet bench and computational laboratories. This research cannot be done without combining the expertise of the "TE community" with functional experimentalists and other researchers interested in comparative and evolutionary genomics. The idea of the conference was to gather these types of researchers and put them in touch with each other, forge collaborations and disseminate information on the state-of-the-art tools and approaches. The response to the meeting was overwhelmingly positive in terms of participation and scientific content.

The core sessions from the conference covered cutting-edge research on transposable elements with a strong emphasis on their impact on genomic stability and evolution. The scientific sessions were complemented by after-dinner workshop sessions focusing on Repbase, computer tools used in annotation and analysis of repetitive DNA and open problems related to the field. On the day of departure the community constituted a provisional international body to coordinate efforts on the systematics and nomenclature of TEs. All the participants were very involved in one-on-one discussions in front of over sixty posters accessible throughout the entire conference. Young researchers were particularly inspired by the opportunity to interact with many senior colleagues who made seminal contributions to the field. Indeed, this allowed them to learn more about the history of the field, and will no doubt be instrumental in developing their own perspective and stimulate contributions to future research. The only downsides were that the conference was too short to take full advantage of the large number of presentations, and to enjoy the scenery at the Asilomar conference center along with the unseasonable weather.

We wish to thank all of the authors of the articles for the special issue and individuals who contributed to the review process for their contributions to both a successful meeting and special issue of Gene. The special issue contains papers that were presented in part or in their entirety at the Asilomar meeting along with additional papers contributed by meeting participants or from individuals in the field. 
Mark A. Batzer Department of Biological Sciences, Biological Computation and Visualization Center, Center for BioModular Multi-Scale Systems, Louisiana State University, 202 Life Sciences Building,

Baton Rouge, LA 70803, USA E-mail address: mbatzer@1su.edu. Corresponding author. Tel.: +1 225578 7102; fax: +1 2255787113 .

Prescott L. Deininger Tulane Cancer Center SL-66, Department of Environmental Health Sciences, Tulane University Health Sciences Center, New Orleans, LA 70112, USA.
Jerzy Jurka

Genetic Information Research Institute, 1925 Landings Drive, Mountain View, California, 94043, USA.

John V. Moran

Departments of Human Genetics and Internal Medicine, 1241 E. Catherine St., University of Michigan Medical School, Ann Arbor, MI 48109, USA.

26 July 2006 